Succussion Splash.

It may be possible to elicit this sign in haemo pneuno. thorax. It is never justifiable to attempt to do so in the early stages; and with $x$ rays at hand it is never necessary.

Metallic tinkling: I do not remember that I have ever met with this sign in gunshot wounds of the chest.

\section{Voice Sounds.}

Modifications of vocal resonance are apt to be mis. loading. The most constant and reliable sign is aegophony, which I have not met with except when there was fluid in the chest. It is usually best heard at or near the upper level of the fluid, and may be localized to a very restricted area there.

Diminished vocal resonance does not always accompany even a large haemothorax; it may be considerably in creased. Occasionally the vocal resonance is increased without any obvious intrathoracic change, even on $x$-ray examination. I do not know what is the explanation of this sign occurring in a chest which has been hit or pene. trated. I have met with it frequently in the first few hours, and have not been able to attach any importance or diagnostic significance to it. Possibly it is due to a partial deflation of the lung insufficient to produce the physical signs of collapse.

In pneumothorax the voice sounds and the cough may acquire a characteristic metallic ring. This metallic ring is also sometimes heard with the inspiratory "souffle in a closed pneumothorax, and indicates that a large opening

communicates with the pneumothorax from the bronchus.
Auscultation is made very difficult "when surgical emphysema is present. If the surgical emphysema is considerable and obvious, it will be recognized at once that auscultation can be of little assistance. Often, how. ever, the emphysema is not'evident; and the auscultatory sounds become very puzzling, particularly when the surgical emphysema is mediastinal, substernal, or sub pleural, and does not extend to the subcutaneous tissues.

Under all circumstances auscultation should reveal the approximate position of the heart, and this is a point which requires determining in every case of gunshot wound of the chest.

\section{Xrays.}

It is impossible to treat chest wounds adequately without $x$ rays. From the time a case comes within reach of surgical assistance to the time he is finally discharged as cured, and even long after if untoward sequelae are suspected; $x$ rays are constantly required. At the outset it is only with $x$ rays that the probsble track of a missilo and its position, if retained, can be ascertained. The position of the heart and diaphragm, their movements, damage to the lung, collapse of the lung, haemothorax, and pneumothorax can only be accurately determined by $x$ rays interpreted in conjunction with physical signs.

Radiography alone is insufficient; the cases must also be radioscopically examined and the parts be seen in movement with fluoroscopic screen, in a sitting-up position if possible.

It must be remembered that pieces of clothing can never, and fragments of bone only rarely, be seen with $\dot{x}$ rays.

\section{General Considerations from the Physician's} Standpoint.

The first consideration is to save life; the second is to restore function as completely and as quickly as possible.

All wounds of the parietes and thoracic contents should receive the surgical attention they require at the eurliest possible moment.

Haemorrhage must be arrested and every possible step taken to early avert infection.

No fluid, whether blood, serum, or pus, must be allowed to collect in the chest. Early and frequent aspiration must be resorted to whether thoracotomy has been performed or not.

Any fluid in the chest is dangerous from two points of view: (a) It is a nidus for sepsis. (b) It interferes with the expansion, not only of the injured, but also of the uninjured lung, setting up conditions favourable to the development and spread of bronchitis, bronchopneumonia, and lobar pneumonia.

Foreign bodies, metal, clothing, and bone, should be romoved whenever possible. They are dangerous, not only from the point of view of immediate sepsis, but from that of subsequent interstitial fibrosis:

Resection and open drainage as formerly practised for empyema is an unsatisfactory operation, and is shown by experience in this war to be rarely necessary if the early treatment, according to modern methods, is not neglected.

1 Duval : War Wounds of the Lung, Preface.

\section{RESUSCITATION WORK IN A CASUALTY CLEARING STATION.}

RICHARD CHARLES, MAJOR R.A.M.G.(T.C.), No. 30 Casualty Clearing Station,

AND

ARTHUR F. SLADDEN, CAPTAIN R.A.M.C.(T.C.), assigtant adviser in Pathologr (Firist army).

THis report deals with work amongst wounded mon (stretcher cases only) received in a tented casualty clearing station during three weeks of activity on a sector of the Western front (September 27th to October 15th, 1918). Until October 4th there were eight surgical teams working, but subsequently only six.

TABLE I.

\begin{tabular}{|c|c|c|c|}
\hline Period. & $\begin{array}{l}\text { Admissions } \\
\text { (wounded). }\end{array}$ & $\begin{array}{l}\text { Opera- } \\
\text { tions. }\end{array}$ & $\begin{array}{l}\text { Percent: } \\
\text { age. }\end{array}$ \\
\hline $\begin{array}{l}\text { Attack on the Canal du Nord } \\
\text { light day'-Sept. } 27 \text { to Oct. } 4,1918 . .\end{array}$ & 1,713 & 479 & 28 \\
\hline $\begin{array}{l}\text { Quiet period : } \\
\text { Four days-Oct. } 5 \text { to Oct. } 8.1918\end{array}$ & 275 & 71 & 26 \\
\hline $\begin{array}{l}\text { Fighting on the Escaut Canal north } \\
\text { of Cumbrai : } \\
\text { Soven days-Oct. } 9 \text { to Oct. 15, 1918... }\end{array}$ & 835 & 353 & 42 \\
\hline
\end{tabular}

TABLE II.-Cilassification of Operations.

\begin{tabular}{|c|c|c|c|c|c|c|}
\hline \multicolumn{4}{|c|}{. } & $\begin{array}{c}\text { First } \\
\text { Period. }\end{array}$ & $\begin{array}{l}\text { Second } \\
\text { Period. }\end{array}$ & $\begin{array}{c}\text { Thixd } \\
\text { leriod. }\end{array}$ \\
\hline Abdominal $\quad \ldots$ & ... & $\ldots$ & $\ldots$ & 31 & 1 & 9 \\
\hline Chest-aldomen ... & $\ldots$ & $\ldots$ & $\ldots$ & 12 & 1 & 1 \\
\hline Chest $\quad \therefore \quad \ldots$ & $\ldots$ & $\therefore$ & $\ldots$ & 15 & 4 & 12 \\
\hline Fractured femur & $\ldots$ & $\ldots$ & $\ldots$ & 23 & 2 & 15 \\
\hline $\begin{array}{l}\text { Fractured fomur w } \\
\text { wounds } \\
\text { Large flesh wounds }\end{array}$ & $\begin{array}{l}\text { vith } \\
\ldots\end{array}$ & $\begin{array}{l}\text { multip } \\
\ldots\end{array}$ & le & $\begin{array}{r}6 \\
40\end{array}$ & $\begin{array}{r}4 \\
1\end{array}$ & $\begin{array}{r}3 \\
26\end{array}$ \\
\hline Kueo-joints $\quad \ldots$ & $\ldots$ & & ... & 38 & 3 & 13 \\
\hline $\begin{array}{l}\text { Multiple wounds: A } \\
\text { fractured tibia. hu } \\
\text { arm, etc. }\end{array}$ & $\begin{array}{l}\text { Ampu } \\
\text { umeiru }\end{array}$ & $\begin{array}{l}\text { tation } \\
\text { us, for }\end{array}$ & & 314 & 56 & $\begin{array}{l}274 \\
\vdots \quad \\
\end{array}$ \\
\hline
\end{tabular}

It will bo noticed that during the third period proportionately far fewcr abdominal cases could be operated upon. 'This was largely due to the increase in distance of the unit from the front line during a time of rapid advance. Most of the cases arrived more than twenty hours after being wounded, and a large number died soon after admission from advanced poritonitis. Tho earlier ab. dominal cases, too, on the wholo responded badly to resuscitation methods, and intravonous methods of treat. ment in such cases werc not often successful, even if they were not obviously contraindicated.

A large number of cases of chest wounds, mostly with other complicating wounds, were admitted, and there were opportunities for keoping cases until better fitted for evacuation.
Total chest
Operations
$\begin{array}{rr}\ldots & 197 \\ \ldots & 93 \\ \ldots & 31\end{array}$

of 21 deaths recorded in the chest wards ons-hall could clearly be ascribed mainly to causes other than the chest wound.' In 33 cases the haemothorax fluid was proved bacteriologically to be infected, strepto. coccus being found in 79 per cent., anaërobe bacilli in 57 per cent., and staphyloeoccus in 50 per cent. 
During this time a total of 450 eases were examined by $x$ rays by Captain Campbell Haddow, of No. 6. Mobile $X$-ray Unit. : Almost all of these vere stretcher cases89 were radiographed for multiple wounds, the abdomen was examined in 85 , the chest in 92 , buttocks in 46 , and knees in 70 cases. Of the other cases, fractured femurs vere numerous and a fair number of foreign bodies were localized in the limbs.

Before giving an account of the work in the resuscitation ward we would mention the volue of gas and oxygen inaesthesia, given by means of a Boyle's apparatus which was at our disposal. For all types of badly shocked eases, and notably also in severe gas infections, it was a very great aid to successful operation and the maintenance of resuscitation.

\section{Resuscitation Ward}

This was a long marquee connected by a covered way with the operating theatre. Well warmed by stoves, it lad twenty-four beds and a small operating bay with two tables, well lit, for intravenous treatment. Cases admitted were not lifted from theiv stretchers unless they wese damp. or in discomfort; the moving of the patients was thus facilitated.

In this ward there were two sisters, one trained orderly, and two general daty men. During the first active period two M.O.'s-one for day and one for night-were avail able; subsequently one only could undertake the work. The successful management of such a ward is very greatly dependent on the skill and untiring patience and energy of the sister's and nursing orderlies, and in this instance nothing was lacking of these essentials.

We aimed at quick resuscitation, oo as to avoid the onset of gas rrangrene; no sharp elinical differentiation is pos. sible between the condition of shock and the toxaemic condition common at the onset of gas gangrene, botil being frequently accompanied by, vomiting and lowered blood pressure.

The general lines of resuscitation treatment were followed; these are sufficiently well known to make a detailed ascount unnecessary here. Waimth applied by hot air, from a paraffin stove, ventilating over tlie patient into his blankets, and from hot-water bottles, was the first and urost important element. 'To quench thirst by water, sweetened lemonade, and other mild drinks was an insistent need and a useful aid; it was necessary to prevent excess of drinking in a good many cases of shock and: abdominal wounds, in which vomiting was persistent. Morphine judiciously given, heroin in chest cases, and camphor as a cardiac stimulant, were all utilized when desirable. So far as possible morphine was not given in leses larger than grain nor more than once in twelve hours-exceptions to this general rule seldom had to be made.

Intravenous injections were largely used in the worst cascs. If there were obvious bleeding not controllable by mechanical means; it was thought better to ayoid methouls which increase blood pressure, otherwise gum infusion was given, unless the case scemed very urgent, when blood transfusion was preferred. Always as soon as possible operation was done. As a general rule, blood trans. fusion was reserved for the post-operative stage when all bleckling points had been secured.

\& An analysis of results sheds some further light on the соннаarative values of blood traisfusion and gum infusion. Althongl this worle was done under circumstances of stress and the treatment was controlled by simple clinical methods of observation only, we do not think a discussion of results is thewby invalidated.

$$
\begin{aligned}
& \text { 'PABLE III.-Rocomls of Intravenows Treatment and Tolats } \\
& \text { Totad adnissions } \\
& \text { Jeaths within } 48 \text { hours }=\ldots \text { failures... } 63=25 \text { per cent. }
\end{aligned}
$$

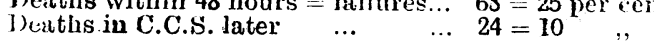

$$
\begin{aligned}
& \text { Totil intravenous treatments ... } \quad \ldots \quad 74 \\
& \text { Deaths within } 48 \text { hours - Fililures... } 23=31 \text { per cent. }
\end{aligned}
$$

For practical purposes cases that died within forty-eight lrours of adrisission have been regarded as failures from the resascitation standpoint.: This classification includes oome deaths from gas gangrene and from abdominal tromdes of sucli sevcrity thint no resuscitation methols conli be expected to avext Heath. The'later deaths liave not been iegirded as trsuscitation failures.
TABLE IV.-Pre-operative and Post-operative T'reatments:

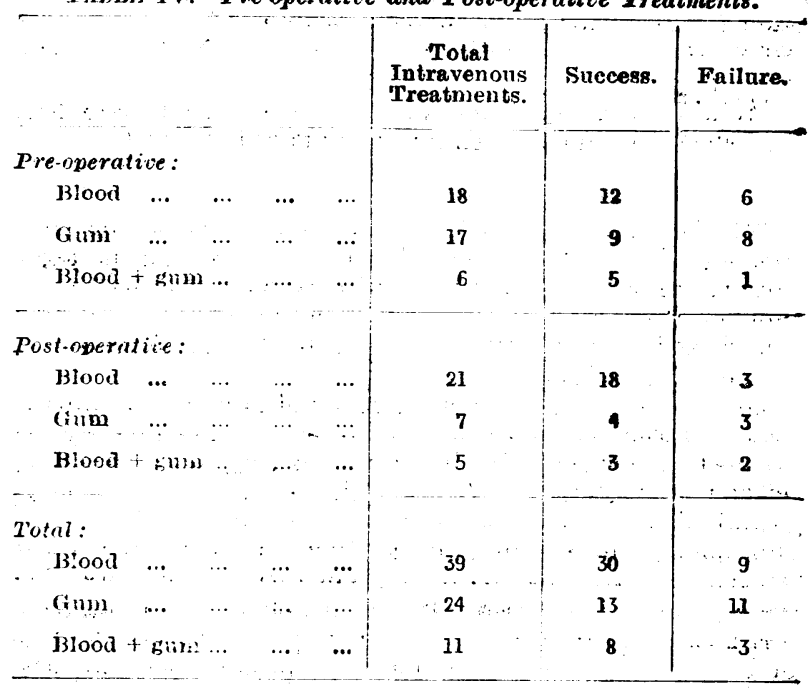

Blood transfusion ox gum infusion was given in seventy. four instances in all, and twenty-three (31 per cent.) of these were "failures" in the sense described. "This group of cases included most of the severe wounds of the limbs, but fewer chest, abdominal, and cranial wounds, which usually were less suitable for intravenous injections, at any rate before operation.

Generally, those exhibiting shock only witl lesser degrees of haemorrhage were given in the first instanco gum infusion, blood transfusion being withleld unless gum showed insufficient benefit. To patients who, before operation, were in fair condition, but on whom a prolonged operation was expected to produce more shock, gum infusion was given with satisfactory yesulis. In cases with evidence of severe haemorrhage, blood was given as early as possible, and we cannot emphasize too strongly the necessity for this measure being applied with no delay in such cases.

In this series, therefore, the giving of blood was restricted to a class of case in worse condition as compared with the "gummed" cases.

In a few post-operative cases in which gas gangrené tissue hád been foúnd a solution of sodium bicarbonate 2 per cent. and glucóse 6 per cent. in distilled water was given with advantage. It was autoclaved at $105^{\circ} \mathrm{C}$ in spring-stoppered bottles. The suigical measures taken, however, had certainly the major share in saving these patients.

After operation in abdominal cases, ant in some major amputations, rectal infusions of sodium bicarbonate 5 per cent. and glucose 5 per cent. were used; the vaino of providing ample fluid in such cases was demonstrated convincingly.

\section{Blood Transfusion Methods.}

The donors were very light walling wounded caises; who volunteered with admirable spirit. There was always time to make the rapid macroscopic grouping test, and, whenever possible, a donor of the same group as the recipient. was used. Failing that, a Group IV donor was taken.

Two transfusion methods were tutilized: (1) The whole blood method asing the Vincient tube, with paraffined surface; and (2) a very simple citrate method; the latter more commonly.

The Vincent tube was coated by meaus of a solution of paraffin in ether, as demonstrated by Major Alton. 'Phis methor of transfusion when successfully performed is very rapid and satisfactory, the facility with which pressure can be applied to force the blood into the recipient's vein is not uncommonly advantageous. - If any relay or mishap occurs, however; the blood drawn off may be wasted through clotting, and so an alternative simple citrate method was adopted by one of as (A. F. S.) and generally used ; it gave quite satisfactory results.

\section{Citrate Methiol.}

- The blool was drawn from the donor by a sliort curved glasa cannuta, or alternativety by a wide hollow needle, and the flow directed"into a sterile graduated measure containing 5 per cont 
citrate solution, in the proportion of 2 ounces for a pint of blood $(1 ; 10)$. This gives finally $\mathfrak{t}$ citrate percentage of just under 0.5 per cent., which we found gives a safe but not excessive margin against clotting. It is essential to ensure excessive margin against clotting. It is essential to ensure adequate admixture of citrate with blood either by stirring or by agitation of the contents of the vessel. It was found convenien to stock this citrate solution ready autoclaved in $2 \mathrm{oz} .(60 \mathrm{c.cm}$. quantities, ready for use. If a hollow needle be used th internal diameter should be from 2 to $2.5 \mathrm{~mm}$., and the length about $4 \mathrm{~cm}$., and it is absolutely essential to have the needle very carefully and recently sharpened; an incision through the skin is an advantage before inserting the needle. Should there be any doubt about the sharpness of the needle, or if the donor's vein is not well swollen, time is saved by exposing the vein and inserting the glass cannula; it was not found necessary to line either cannula or needle with paraffin. Care is needed in adjusting pressure to donor's upper arm, sufficiently but not too stiongly, so that a brisk stream of blood is ensured. This is readily accomplished by the use. of a blood-pressure armlet adjusted to about $50 \mathrm{~mm}$. pressure.

The citrated blood, kept warm at $40^{\circ} \mathrm{C}$, was then run into recipient's vein by means of a simple funnel, tube, and glass colpiots vein by means of a simp.

nnula as used for saline infusions.

The apparatus required is quickly prepared for use, and the method is at least as free from pitfails as any other wo have tried.

It was found that donors felt little ill effect from the loss of a pint of blood, but that further withdrawal soon dis. turbed them. In view of the large number of donors utilized it was felt undesirable to take much beyond this quantity as a rule; in order to increase the blood pressure rather more, we adopted latterly the practice of adding to the pint of blood a pint of other fluid, preferably gum solution. This was done from motives of economy in donors solely, and would only be advised when the degree of blood loss was not extreme. In such cases two pints of blood would be indicated, and two donors of the samo group might well be used.

In a few very severe cases a second blood transfusion was given later after operation with very beneficial effect.

From a review of this collection of cases it can only be deduced that blood transfusion has a distinct advantage over gum infusion. Analysis of both pre-operative and post-operative cases gives this impression, and previous independent experience of one of us (R. C.) witli forty blood transfusions, and the other with a similar number of gum infusions, also favoured the former method At the same time it is recognized that no two cases are alike in respect of their wounds, their powers of resistance, and ho circumstances of exposure and infertion.

There is certainly a class of case thich derives suffi cient benefit from "gum infusion; on the other hand, some patients who when treated with gum infusion failed to improve showed great benefit from a subsequent blood transfusion. Our experience in such cases points to the necessity in these severer cases of haemorrhage for pro ceeding without delay to a blood-transfusion. Some case of pure shock without loss of mucli blood seem to derive no benefit, unfortunately, from either method

In abdominal cases, where haemorrhage was the im portant factor, blood given after operation-or, if more urgently noeded, during the operation-undoabtedly saved lives; formerly this type of case after operation failed to rally, and died. One of us (R. C.). liad two such cases lately; after operation and before transfusion the pulse rate was 150 and pulse volume poor. In each case a litre of blood was transfused; twelve hours later the pulse was of good quality, ranging between 90 and 100 , and each pationt made an uneventful recovery.

We are quite opposed to the indiscriminate use of blood transfusion when other methods may be confidently pected to suffice, but we are convinced that there is a class of case in which blood transfusion is the only known treatment likely to succeed, and for such the use of donors and their blood appears amply justified both from the medical and the military standpoint; it is no light thing for the soldier to know that every resource, including blood transfusion, if necessary, will bo invoked to bring about recovery of his wounds.

Reference to the table of the results of intravenous treatment shows a uniformly lower proportion of failure with blood than with gum, and if the severe abdominal cases and gas gangrene deaths be eliminated, this difference is only accentuated.

This analysis leads inevitably to the conclusion that blood transfusion had giveater value than "gum infusion, and the fact that in this series blood was given only to cases which appeáred in worse condition tends to make the contrast stronger.

With either method there is usually an immediate response in, the pulso rate and quality, but genera improvement is by no means always obvious at once; $i$ would be a mistake to judge the value of either treatment only by the immediate effect; the condition of the patien three, six, or twelve hours later is more important than his state five minutes after the fluid has entered his veins and, judging by this later clinical condition also, the advantage of blood over gum has impressed us.

We have not seen in this series any ill effects ascribable to gum infusions, though these are spoken of by some surgeons; nevertheless, it is well to emphasize the great importance of running the gum in slowly-about fifteen minutes for $500 \mathrm{c.cm}$. is not too slow; if this precaution bo not taken, vomiting, rigors, and athetotic movernents are likely to occur. When slowly administered at the proper temperature $\left(37^{\circ}\right.$ to $40^{\circ} \mathrm{C}$.) the infusion has more often than not a distinctly sedative effect.

Resuscitation work has its depressing side-many cases are brought in obviously moribund-but its succéssful side renders it undoubtedly worth while.

If there be a shortage of surgical teams it is difficult to arrange for the edequate working of such a ward for it is hardly practicable to remove a surgeon from the theatre where he can operate upon, say, twelve cases in twelve hours, in order to spend his efforts on fifteen to twenty badly wounded men, of whom at most seven or eight cai possibly be saved by present known methods. Further, if there are insufficient operating surgeons, operable cases will have to be sent to the base for operation, and these very cases may arrive there in condition as acute as those which needed resuscitation at the casualty clearing station so that in present circumstances one cannot look to tho skilled surgeon to do this work

It is for the administrative authorities to consider whether the necessary medical officers for this work can be found elsewhere; their services can be very valuable in this field.

\section{Concliqsions.}

1. Resuscitation methods such as have been developed during the war are of the utmost value in war surgery, It is evident that these methods will be equally applicable in the everyday surgery of accidental injuries and in obstetric work

2. Gum infusion is an advance on the infusion of normal saline, and may enable a patient who has not lost blood excessively to be operated upon successfully. It is not evident that the benefit due to gum can extend over more than a few hours.

3. Where haemorrluage, is severe, blood transfusion is tho only reliable treatment, and should be given without delay. In such cases it is much superior to gum. In blood trans. fusion we found no important difference between whole blood and citrated blood.

4. Previous to transfusion a blood-grouping test ought to be done in every case. If possible, the donor should be of the same group as the recipient; failing that, recourse must be had to a Group IV donor.

5. We wish to emphasize the need for observing the strictest surgical aseptic techniquo towaids donor and recipient. The donor must be free from known general infections, such as syphilis or malaria, in so fai as can bo ascertained by inquiry.

\section{COLLOIDAL MANGANESE IN GONOHKHOEAL OPHTHALMIA.}

\section{BY DONALD MGFARLANE LIVENGSTONE, MED.,} Ch.B., B.Sc:, Temporany Gaptis

ETE SPECIALIST, CONNAUGHT HOSPITAL, ALDERSHOT.

IT will be generally conceded that the treatment of gonorrhoeal conjunctivitis in its severer forms brings but-little satisfaction to the ophthalmic surgeon; and any remedy which promises to control the diseáse more effectively is worthy of prolonged test. "I häve recently used colloidal manganese in three cases of gonorrhoeal ophthalmia, and all have made excellent progress; the last case, which is reported here, being espocially noto. 